information between technicians working in this field, and more especially between technicians in contiguous regions. A ringing programme was recommended to include at least 100,000 birds over a period of three yoars, and a budget drawn up for such a programme. Another recommendation dealt with the need for investigations on the physiology and parasitic diseases of quelea as being indispensable in determining fresh control methods.

\section{New Stomatopod Crustaceans in West Africa}

Is November 1956, Dr. D. T. Gauld, of the University College of Ghana, sent to the British Museum (Natural History) three small Stomatopods, collected at Labadi, West Africa. One of these proved to be an immature specimen of a Lysiosquilla; the other two specimens were labelled Squilla pallida, but this identification proved to be incorrect. Later, two further specimens identical with those submitted by Dr. Gauld were found among a collection of Squilla africana Calman from Accra. It was apparent that these four specimens belonged to an undescribed species of Squilla as they did not agree with any known West African species, or with the doscriptions of any of the known Eastern Atlantic ones. The name Squilla labadiensis has been given to this new species, which is described by $R$. W. Ingle in the September issue of Annals and Magazine of Natural History $(2$, No. $21 ; 1960)$. During the course of describing Squilla labadiensis, Ingle re-examined several West African specimens of Squilla in the British Museum (Natural History) collections. In particular, among $a_{0}$ collection presented to the Museum by Mr. A. R. Longhurst, it was discovered that several specimens labelled Squilla mantis had been wrongly determined, and these specimens were identified as Squilla intermedia Bigelow, hitherto known only from the Gulf of Mexico and Little Bahama Bank, and the range of which is now extended to the West African coast. The description of Squilla intermedia is included in the paper.

\section{Canavanine in Leguminosae}

THe amino-acid canavanine is known to be present in the free state only in members of the Leguminosae. It occurs in the seeds and its synthesis has been reported in rooted leaves of Canavalia sp. Its presence can be detected by simple chromatographic techniques. B. A. Birdsong, R. Alston and B. L. Turner have now reported on a systematic study of the distribution of this substance in 161 species, representing 78 genera, of Leguminosae, and have discussed the impact of their findings on the phyletic grouping in this family. These results are supplemented by data, variously collected, by other authors, to yield a total of 219 investigated species representing 109 genera. Of these, 68 species belonging to 32 genera have canavanine in their seeds. Canavanine has not been found in the sub-families Mimosoidea or Caesalpinioideae. In the sub-family Papilionoideae it has not been found in the tribes Podalyrieae and Sophoreae. At least one species from each of the other tribes produces canavanine. In three genera, some species produce canavanine whereas others do not. These data are presumed to be of taxonomic significance and have been interpreted as support for chromosomal information, indicating that the tribes Mimosoidea and Caesalpinioideae diverged relatively early from the 'stem' line which is now represented by the Papilionoideae (Canad. J. Bot., 38, 499 ; 1960).

\section{New Nature Reserve}

The Nature Conservancy has declared a new national Nature reserve of 1,363 acres at Invernaver, near Bettyhill, on the north coast of Sutherland. The reserve includes woodland, heath and sand-dunes. Its subsoil is limestone, and this brings in a number of rare and local plants, including the Scottish primrose Primula scotica, the mountain avens Dryas octopetala, and the purple mountain milk-vetch Oxytropis halleri. The attractive little spring squill Scilla verna also grows in the reserve, and there is a moss that grows nowhere else in Britain. The breeding birds of the reserve include the greenshank, redthroated diver and ring ouzel.

\section{Symposium on Zooplankton Production}

Following the success of the symposium on primary plankton production held in Bergen in 1957, it is proposed to hold a symposium in Copenhagen in 1961 entitled "Zooplankton Production". It will be held towards the end of the annual session of Intermational Council for the Exploration of the Sea during October 8-10. The symposium is planned to include: two sessions on methods of estimating zooplankton, methods used at sea and in the laboratory, methods of assessment of standing crop and production; one session on the food of zooplankton, the trophic relationships of the organisms, and regeneration of nutrients ; one session on behaviour, including vertical migration, distribution, speed of movement and zooplankton as a possible source of sonic scattering layers; one session left open for extra papers and discussion of recommendations. To keep within the schedule, and yet allow time for the very valuable discussions, the papers at the first four sessions will be by invited speakers only. Papers for consideration for the fifth session will be welcomed, at this stage by title only with a paragraph of explanation if this is not clear in the title. The organizing committee includes: Dr. J. H. Fraser (convener), Marine Laboratory, P.O. Box 101, Victoria Road, Aberdeen; Prof. E. Steemann Nielsen (Copenhagen); Prof. J. Krey (Kiel); Dr. Gunnar Thorson (Helsingør). Those who intend to be present should notify the convener as soon as possible.

\section{"Educating the Whole Man"}

Is an article, "The Problem of Freodom and Efficiency in Universities", in Science and Freedom for October and in a broadcast talk, "Dry Rot and Redbrick", Dr. A. P. Rowe pleaded earnestly for a thorough reconsideration of the relations between teaching and research in British universities. He suggested a searching inquiry into the quality of both, as well as into the balance between them, and also that changes in the structure of the administration of the universities might facilitate the promotion of more effective and stimulating terching, and the elimination of much of the trivial investigations which now pass for research. A sentence in the leading article in Nature of January 7 (p. 2) unwittingly misrepresents Dr. Rowe's mind. So far from rejecting any idea of a broad education, he is concerned that the universities of Great Britain are failing to provide that vital something that was once given by the homes from which their students came; and although he advocates that more research should be carried out in research institutes rather than in university departments, such institutes should be, he thinks, an integral part of the university. 